\title{
Remarks on Collaborative Maritime Transportation's Problem Using System Dynamics and Agent Based Modeling and Simulation Approaches
}

\author{
Vanina Macowski Durski Silva ${ }^{1}$, Antonio Sérgio Coelho ${ }^{1}$, \\ Antonio Galvão Novaes ${ }^{1}$, and Orlando Fontes Lima $\mathrm{Jr}^{2}$ \\ ${ }^{1}$ Federal University of Santa Catarina, Department of Production and Systems Engineering \\ Trindade, Florianópolis, Brazil, 88040-970 \\ vaninadurski@gmail.com \\ ${ }^{2}$ State University of Campinas, Department of Civil Engineering, Campinas, Brazil
}

\begin{abstract}
This paper deals with the collaborative maritime transportation problem which can be modeled with two different approaches: System Dynamics (SD) and Agent Based Modeling and Simulation (ABMS). In the literature concerning this topic they are indicated to model systems containing large numbers of active objects (industries, people, vehicles, warehouses, products) and their applications vary according to the required level of abstraction, which can consider more or less involved details. In order to contribute with the decision-making, one important logistic problem is adopted as example; and in the sequence, a comparative analysis between these two possible techniques to examine such problem is presented. Finally, this study describes how to model this problem using these techniques which improve the analysis of the global behavior of the supply chain. For further implementation, some recommendations are given.
\end{abstract}

Keywords: Manufacturing industries, System Dynamics, Maritime transportation, Decision taking, Collaboration.

\section{Introduction}

The understanding of logistics as the integrated planning, control, realization and monitoring of all information and products is becoming more and more dependent on technological innovations. One reason for this is the increasing complexity in combination with a high incidence of factors. Besides, most of people think of complexity in terms of number components in a system or the number of combinations one must consider on making decision, dynamics complexity, in contrast, can arise even in simple systems with low combinatorial complexity. The Beer Distribution Game provides an example: complex and dysfunctional behavior arises from a very simple system whose rules can be explained in 15 minutes [1]. Dynamics complexity arises from the interactions among the agents over time.

In order to support these requirements the integration of new technologies and analysis tools has become necessary. The recently trend is the developments within 
Simulation techniques which are moving beyond the classical methods, propitiating a better overview of the systems, such as logistic and supply chains systems.

In these particular systems, there are numerous elements and actions involved like suppliers, warehouses, trucks, ships, industries, routes and customers, not to mention all. They have been influenced by the changes generated with the globalization which highlight the companies' inability to aggregate internally all the required skills to their survival. Consequently, relationships among companies have become a forceful differential in companies' facilities, which can contribute to their success in the market.

Since taking decisions involves a complex system, companies need to create different scenarios to better analyze the behavior of the global supply chain. Thus, modeling logistic and supply chains scenarios are a challenging work, but it can be done with the use of good tools. The aim of this paper is to discuss a possible way to do it; thus, it contains five main topics including this brief introduction. The second topic exposes one real logistical problem which is difficult to optimize but with the aid of some Simulation techniques can be better analyzed. The third topic presents a comparative analysis between the two possible techniques, System Dynamics and Agent Based Modeling and Simulation, to examine such problem and, the fourth topic comments about how to interpret the mentioned logistical problem using the concept of these techniques. Finally, recommendations for further studies are given at the end of the work.

\section{Collaborative Maritime Transportation's Problem}

When studying logistic problems the initial step to better understand it is recognizing the main system's elements (industries, warehouses, suppliers and products) and their interdependences. In this topic the collaborative maritime transportation problem will be presented, which can be modeled based on SD and ABMS.

\subsection{Maritime Transportation in Case of Exportation}

When deciding to export, industries should observe the stages of the process, aiming at knowing its client market, its demands, habits and characteristics. According to [2] it should also define other factors like: transportation mode, specific packing for its product in order to maintain its integrity, freight form to be adopted in the negotiation, as well as the carrier to perform the transportation, besides considering the insertion of an intermediate agent (freight forwarder) or NVOCC (non vessel operator common carrier) in the negotiation.

Since most of the exportations are performed through maritime transportation, the focus in this example should only discuss maritime exportation. Figure 1 shows the main stages of the exportation mechanism.

In maritime transportation the most important active agents are the industries, land carriers maritime carriers, maritime agency, NVOCC, load freight contractor, multimodal transport operator and cargo broker. Upon the performance of a sale or purchase, a delivery destination of the products should be established, where the liabilities should be shared between the vendor and the purchaser. Such liabilities comprise costs and risks on the transaction as well as accordance in the definition of deadline and volume to be transported. 


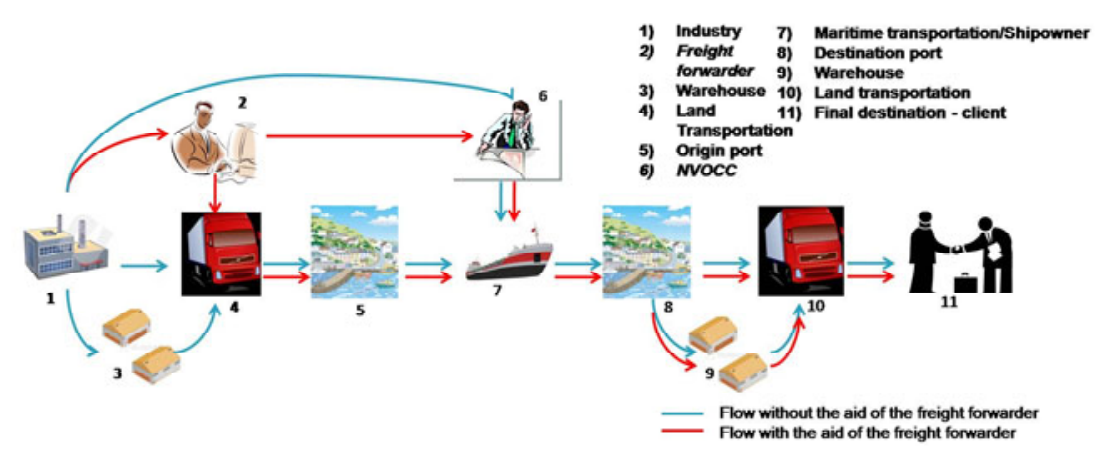

Fig. 1. Stages of exportation mechanism Source: [2]

\subsubsection{Transport Negotiation}

Normally, in case of transporting general cargo or even pallets, the export industries or the freight forwarder should be able to perform booking of a conventional ship in a regular line (trough a NVOCC or not).

The next step is the decision of a port, as well as the terminal and shipowner/maritime carrier to be used. In the same time, should be evaluated transportation costs, traffic time and deadline for delivering the products. One possibility to be considered is the convenience to have a safety warehouse in another city, which means, to maintain an inventory in any region to solve quickly delivery problems. As a consequence of the planned logistics it is possible to reduce the costs of transportation, inventory level in industries, loss of time on traveling and, finally, problems in the delivery and compliance with sales contract.

It is important to mention the real situation where frequently the maritime carriers decide in a Freight Conference the prices to be practiced in the maritime market. In these situations, industries acting alone do not have enough power to better negotiate with them. In situations like this, the concept of collaboration can be applied in order to create groups of industries with the same goal, negotiating with the maritime carriers in order to stop the oligopoly created by them. To a better comprehension about Collaborative Transportation, see [3].

\subsubsection{How to Operate in Exportation? Individually or in Collaboration?}

After defining the general maritime exportation mechanism, it is observed that it is very ample, comprising several variables and requiring updates regarding volumes, capacity of the ships, prices, maritime fees, extras fees and law among others. One point to be discussed is how the export industries involved in this mechanism should act: individually or in collaboration? If isolated, each exporter industry should analyze the manner to perform the transportation of its products, considering all the stages showed in Figure 1.

Adopting the collaboration concept, another possibility is searching for help from a freight forwarder who arranges such stages. If possible, this professional can join cargoes from several industries in order to achieve economies of scale in the transportation. It can be also performed directly through partnerships among export industries, without the addition of the freight forwarder. 
Through this collaboration in the transport activity it is observed the formation of global logistics networks articulating productive areas, not only expanding service coverage but also frequency, efficiency and circulation rate of the products [4].

In this example, the number of involved agents and their transactions can be a limiting factor for optimization techniques. In such case, this problem can be modeled with the use of the proposed tools: SD and ABMS.

\section{Simulations Methods}

\subsection{Comparative Analysis}

According to [5] problems can be generally arranged on the scale with respect to the level of abstraction. Normally, supply chains can be modeled in middle to high abstraction range. SD is a traditional approach while ABMS is relatively new. SD deals with continuous processes whereas ABMS deals with discrete time. Each approach corresponds to an abstraction level: SD has the highest abstraction level and ABMS can be used in all of abstraction levels, varying the nature and scale of the elements. Since logistic and supply chain problems involve several elements which cannot be modeled with such detail (varying from medium to high level of abstraction), the ABMS and SD approaches fit better in their analysis. Thus, in the next topics both will be better presented.

\subsection{System Dynamics}

SD is a continuous modeling and simulation method. However, the method main differential lies in its ability to represent capacity non-linear relationships between the several system variables [1]. This characteristic is extremely useful to understand systems behavioral patterns and its long-term behavior, front the adoption of different management polices and scenarios [6]; [7].

As consequence, SD models are aggregated and have high abstraction level [5]. Thus, some of the methods' limitations are: the difficulty on representing detailed processes as in discrete event processes; the difficulty on modeling activities with fixed duration time and the inability to model complex entities which possess characteristics of decision and heterogeny [7].

\subsection{Agent-Based Modeling}

Agent-based Modeling and Simulation (ABMS) is a computational method widely used to understand and analyze systems composed of many interacting individuals [7]; [8].

According to [7] the basic principle of the ABMS is: systems are larger than the simple sum of its components and the behavior of the system emerges from the interrelations between these several components. Each one these components has its own set of rules and behaviors, which provides them the ability to affect in greater or lesser degree the system's global behavior.

Unlike other paradigms or modeling methods discussed, there is lack of a universal definition for the key-concept of ABMS [9]. For the authors this deficiency occurs in function of the diversity of science areas that use the concept of agent. One 
consequence of this limitation is reflected in the ABMS tools. Many of them are not user-friendly. This feature was very important for the popularization of SD method.

Other important method's drawback is the high computational requirements of ABMS when it comes to modeling large systems. ABMS looks at a system not at the aggregate level but at the level of its constituent units. In this case, simulating the behavior of all units can be a extremely intensive computation and therefore time consuming [10].

\section{Practical Application and Outlooks}

\subsection{Application of System Dynamics}

When using this technique the first step is to define the system's boundary. For this problem it was decided to consider the actions of the manufactured industries and the maritime carriers. Such consideration represents a simplification of the system showed in Figure 1.

In the second step were defined the agents' objectives and the main variables which influence these objectives. The exports industries' objectives contemplate increase its competitiveness in the market and reduce logistics costs, while the maritime carriers' objectives are the reduction of offer-demand gap and the increase of its profit. These objectives can be reached based on the agents' actions like: increasing collaboration among the export industries and changes in the maritime transportation offer.

The decisions taken by the agents in the way to reach their objectives cause actions and reactions as showed in Figure 2 through the Causal Loop Diagrams. The necessity to reduce logistics costs leads the exporter industries to increase the collaboration with others. As a reaction, the increase of the bargaining power occurs which leads to the freight price decreases and consequently, logistics costs reduction. This reaction is showed in the reinforcing $R l$ looping.

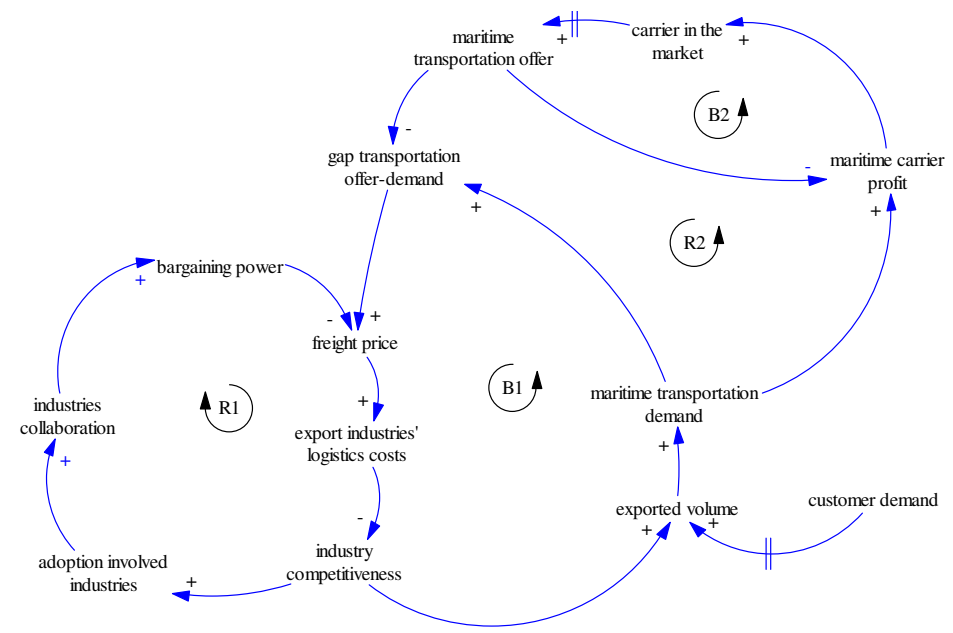

Fig. 2. Reinforcing and balancing loopings between exporters and maritime carriers' negotiation 
With the export industries' logistics costs reduction, the export industries increase their competitiveness in the market impacting on the exported volume. Consequently the maritime transportation demand is affected which changes the gap transportation offer-demand. This influences the freight price and also the logistics costs, according to the balancing Bl looping. The changes in the maritime transportation demand affects the maritime carrier profit, impacting the number of carriers in the market, which changes the maritime transportation offer and consequently, the gap transportation offer-demand. This is showed in the reinforcing $R 2$ looping. Finally, in the balancing $B 2$ looping is showed the impact in the maritime transportation offer over the maritime carrier profit.

\subsection{Application of Agent Based Modeling and Simulation}

As previously mentioned, agent-based modeling does not have a set of standard for the model development and agent representation such as happen on SD method. According to [7] the general steps in building an agent model are the following:

1. Agents: Identify the agent types and other objects (classes) along with their attributes.

2. Environment: Define the environment where the agents will live in and interact with.

3. Agent Methods: Specify the methods by which agent's attributes are updated in response to either agent-to-agent interactions or agent's interactions with the environment.

4. Agent Interactions: Add the methods that control which agents interact, when they interact and how they interact during the simulation.

5. Implementation: Implement the agent model in computational software.

In the maritime transportation problem, the main agents consist of industry, NVOCC, 3PL, maritime carrier, land carrier and customer. A convenient way of representing these agents is through a UML (Unified Modeling Language) class diagram. For example: the industry agent is represented by the following attributes: the agent's name, shipment, deadline, costs, cargo and cargo destination.

In the maritime model, the environment consists of the market where the agents negotiate the transportation. For example: an environment variable could be the offered routes and their related prices. The next step is to specify how the agent attributes are updated during the simulation in response to the agents' interactions both with the environment and/or other agents. As example, an interaction can be the choice of a maritime carrier or the choice of the route.

In the fourth step occurs the definition of the methods that control how the agents will interact. In this model, in every time period the following sequence must be solved: search a partner; choose a NVOCC and/or a carrier and finally, send the shipment. The representation of the agents (their attributes and rules) can be seen in the UML class diagram in Figure 3.

Finally, the last step contemplates the implementation of the model in an appropriated tool. There are several available modeling tools and the selection step must be done in the step ahead which was not performed in this work. 


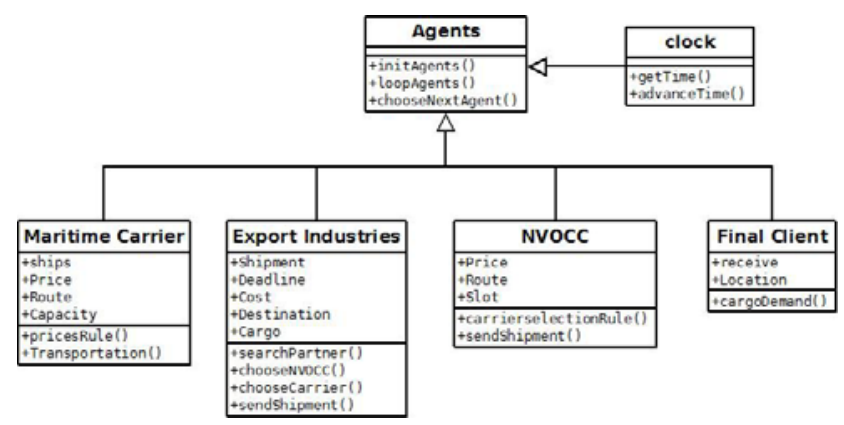

Fig. 3. Agent UML class diagram

\section{Conclusions and Further Studies}

In this work the collaborative maritime transportation's problem was briefly presented, showing how the interactions among the involved agents occur. After it, two simulation techniques were selected and a comparative analysis between two of them (SD and ABMS) were done. This analysis presents the main differences, drawbacks and technical limitations.

Considering each technique has a different approach for the problem, in section 4 was presented in a summarized way two proposals for modeling the problem in study. As expected, the SD model showed an aggregate view of the problem where the borders among the different agents of the system were blurred. In this case the analysis' point of view is in the policies development, which can support the collaboration improvement and consequently, cause a change in the agents' forces and the system long-term behavior.

On the other hand, the ABMS model permits a better definition of the agents' behaviors and rules. This characteristic allows visualizing how the collaborative behavior will emerge from the interactions between the agents and between the agents and the environment.

For future studies these models will be implemented through the appropriated computational tools which will be selected after a comparative analysis between the several available tools.

Acknowledgments. CNPq/Fapesc Project $n^{\circ}$ 1.0810-00684 (Pronex), Capes/DFG Bragecrim Project $n^{\circ} 2$ and CNPq Project n ${ }^{\circ} 402410 / 2009-2$.

\section{References}

1. Sterman, J.: Business dynamics: systems thinking and modeling for a complex world. Irwin/McGraw-Hill, Boston (2000)

2. Silva, V.M.D., Loureiro, S.A., Novaes, A.G.N., Scholz-Reiter, B.: Kollaborativer Seetransport: Beziehungspolitik der brasilianischen Exportkette für Fertigungsprodukte. Industrie Management 27, 23-26 (2011) 
3. Silva, V.M.D., Coelho, A.S., Zago, C.A.: Collaborative Transportation Management (CTM): uma nova ferramenta de apoio à cadeia de suprimentos. Revista Tecnologia 30(2), 265-272 (2009)

4. Souza, E.A.: América Latina e sistema marítimo portuário mundial. Anais do 120 Encuentro de geografos de America Latina, 3-7 de abril, Montevideo, Uruguay (2009)

5. Borshchev, A., Filippov, A.: From System Dynamics and Discrete Event to Practical Agent Based Modeling: Reasons, Techniques, Tools. In: The 22nd International Conference of the System Dynamics Society, Oxford (2004)

6. Sanches, L.M.: Análise do acúmulo da demanda logística no final do periodo de comercialização: um modelo de dinamicas de sistema para o setor de bens de consumo brasileiro. Tese (Doutorado) - Departamento de Geotecnia e Transportes, Universidade Estadual de Campinas, Faculdade de Engenharia Civil, Arquitetura e Urbanismo, Campinas (2009)

7. North, M.J., Macal, C.M.: Managing business complexity: discovering strategic solutions with agent-based modeling and simulation. Oxford University Press, New York (2007)

8. Gilbert, N.: Agent-based models. Sage Publications, Los Angeles (2008); Quantitative applications in the social sciences, 153

9. Macal, C.M., North, M.J.: Tutorial on Agent-Based Modelling and Simulation. In: Euhl, M.E., Steiger, N.M., Armstrong, F.B., Joines, J.A. (eds.) Proceedings of the 2005 Winter Simulation Conference (2005)

10. Bonabeau, E.: Agent-based modeling: methods and techniques for simulating human systems. Proc. Natl. Acad. Sci. U.S.A. 99(suppl. 3), 7280-7 (2002) 